\title{
MODOS DE RECONCILIACIÓN. DOS REMAKES DE FILMES DE LOS SESENTA EN EL CINE ARGENTINO CONTEMPORÁNEO
}

\section{Reconciliation Modes. Two Remakes of 60 s Films in Contemporary Argentine Cinema}

\author{
Dr. Jorge SALA \\ Universidad de Buenos Aires. Profesor Ayudante Doctor (Jefe de Trabajos Prácticos), Argentina \\ E-mail: jorgesala82@hotmail.com
}

Fecha de recepción del artículo: 13/03/2017

Fecha de aceptación definitiva: 29/04/2017

\begin{abstract}
RESUMEN
El artículo analiza dos casos de remakes de los años sesenta en el cine contemporáneo argentino: Aniceto (Leonardo Favio, 2008) y La patota (Santiago Mitre, 2015). El objetivo es examinar las transformaciones y continuidades entre los textos fuentes y las obras subsidiarias partiendo de una perspectiva atenta a reconocer tanto las cuestiones inmanentes como los aspectos procesuales y pragmáticos intervinientes en estas operaciones de reescritura. La hipótesis central a demostrar propone que ambas películas generan, por caminos disímiles, una lógica de reconciliación con el pasado para construir una perspectiva sobre el presente. En Aniceto, el gesto conciliador se produce bajo la forma de una síntesis de las dos tendencias que caracterizaron el cine de Favio: una primera asociada a la estética de la modernidad frente a la segunda en la que predomina el acercamiento al universo popular y a otras prácticas pertenecientes a la cultura masiva. El film de Santiago Mitre reúne, por su parte, una película de un director vinculado al modelo clásico (Daniel Tinayre) revisada a la luz del cine actual. A su vez, La patota unifica las condiciones de una gran producción comercial con la lógica de funcionamiento y la estética propias del «cine anómalo».
\end{abstract}

Palabras clave: remake; cine argentino; Leonardo Favio; Santiago Mitre; reconciliación.

\begin{abstract}
The article analyzes two contemporary movie remakes of the 60s cinemas in Argentina: Aniceto (Leonardo Favio, 2008) and La patota (Santiago Mitre, 2015). The objective is to explore the transformations and continuities between the source texts and the later subsidiary texts. It tries to recognize the immanent issues, the procedural and pragmatic aspects involved in these rewriting operations. The central hypothesis to be demonstrated proposes that both films generate, through different paths, a reconciliation with the past constructing a perspective through the present. In Aniceto, the conciliation gesture occurs in the form of a synthesis of the two tendencies that characterized Favio's cinema: a first one associated with the aesthetics of modernity versus the second one, in which the approach to the popular universe and other practices belonging to the mass culture predominates. For its part, the work of San-
\end{abstract}


tiago Mitre assembles a film of an Argentinean classic movie maker (Daniel Tinayre) under the light of the current cinema. Besides, La patota ties the characteristics of a great commercial production with the structure and aesthetic of the «anomalous cinema».

Key words: remake, argentinean cinema, Leonardo Favio; Santiago Mitre, reconcilement.

\section{INTRODUCCIÓN}

La práctica de reversionar películas del cine argentino actual ha experimentado en los últimos años un interés creciente en distintos países. La repercusión en la taquilla, sumada a cierto afianzamiento en formatos genéricos reconocidos, hicieron que algunos títulos recientes provenientes de esa nacionalidad fueran reutilizados en el marco de otras cinematografías. En este sentido, pueden mencionarse un número considerable de títulos que en un corto período apuntaron a replicar, con suerte variada, los valores estéticos y económicos de las originales: Nueve reinas (Fabián Bielinsky, 2001) / Criminal (Gregory Jacobs, 2004), Elsa \& Fred (Marcos Carnevale, 2005) / Elsa \& Fred (Michael Radford, 2014), El secreto de sus ojos (Juan José Campanella, 2009) / El secreto de una obsesión (Secret in their eyes, Billy Ray, 2015), No sos vos soy yo (Juan Taratuto, 2004) / No eres tú soy yo (Alejandro Springall, 2010) o Un novio para mi mujer (Taratuto, 2008), con múltiples versiones procedentes de Corea del Sur - All about my wife (Kyu-dong Min, 2012)-, Italia -Un fidanzato per mia moglie (Davide Marengo, 2014)-, México -Busco novio para mi mujer (Enrique Begne, 2016) - y Chile -Se busca novio... para mi mujer (Diego Rougier, 2017).

En el juego de proximidades, apropiaciones y referencias explícitas estructuradas fundamentalmente en las transformaciones espaciales de los acontecimientos narrados, el rol cumplido por Hollywood resulta determinante dentro de este proceso. Por una parte, la intervención aparece de manera directa, como en aquellos filmes exitosos que sirvieron como antecedente para la concreción de relatos establecidos dentro del esquema de producción industrial norteamericano. En otros, como en los remakes basados en las películas de Juan Taratuto, la relación con esta cinematografía, aunque oblicua, no es menos evidente. Ancladas en un género como el de la comedia romántica, transitado asiduamente por el cine hollywoodense y replicado en otros países, las distintas variantes de No sos vos soy yo y Un novio para mi mujer adscriben a una suerte de lenguaje universalmente reconocido que facilita su traslación a zonas y culturas tan diversas entre sí como las de Asia, Europa y Latinoamérica. Más allá de poder concebirse, entonces, como ejemplares de lo que la teoría anglosajona denomina cross-cultural remakes (Horton y McDougal, 1998), estos largometrajes dan cuenta de la patente hegemonía de un modelo que los unifica y que, acaso también, determina su existencia y su fortaleza.

Si bien el listado de filmes mencionados permite constatar la vigencia de un modus operandi para nada novedoso dentro de las estrategias del cine industrial (norteamericano o de otras latitudes), a su vez coloca en un segundo plano otras manifestaciones llevadas a cabo en los mismos años. En el marco de la producción argentina reciente, dos largometrajes se distinguen de los anteriores. Reconociéndose abiertamente como remakes, estos guardan, no obstante, una cantidad de diferencias que los ordena bajo una nueva lógica de funcionamiento, innovadora para el cine nacional. La distancia -no menor- que mantienen con el otro grupo radica en su decisión de instituir un diálogo con la propia tradición local. Más específicamente, el contacto producido por estos filmes encuentra sus interlocutores en piezas de los años sesenta. Fue este un momento crucial para un cine que, como en gran parte del mundo, se debatía entre el ocaso del modelo clásico y la emergencia y consolidación de la modernidad. De ahí el carácter singular que asumen estas recuperaciones. 
Leonardo Favio, un realizador fundamental salido de las huestes de la renovación autoral de ese momento, estrenó en 2007 lo que sería su último largometraje previo a su muerte, Aniceto, tomando como punto de partida su segundo trabajo, Este es el romance del Aniceto y la Francisca, de cómo quedó trunco, comenzó la tristeza y unas pocas cosas más (1966). Por su parte, en 2015 se dio a conocer La Patota ${ }^{1}$ (Santiago Mitre), nueva versión de la película homónima dirigida en 1960 por Daniel Tinayre. Aunque minoritarias, estas no dejan de traslucir ciertos focos de interés para el análisis. La voluntad de remitirse a unas obras distantes implica, más que un alejamiento, un quiebre respecto a la habitual inmediatez con la que el cine industrial recupera filmes exitosos para apropiárselos. Se trata, en suma, de dos formas de «retro-remakes» (Look, 2016, pp. 278-279), pero aquí ubicadas con independencia de las habituales aspiraciones comerciales que pretenden multiplicar un suceso a través de su continuación o de la repetición de unos contenidos cuya efectividad ya fue puesta a prueba en contextos diferentes.

Por otro lado, la decisión de reposicionar unas manifestaciones autóctonas (claramente autorreferencial en el caso de Favio, narrativa en el de Mitre) supone un corrimiento que abre una vía propicia para establecer algunos interrogantes: ¿Cuáles son las implicancias del diálogo con el pasado elaborado por estas películas? ¿De qué manera se sirven de la estética de un momento específico -los sesentapara revisitarla y formular un discurso desde el ahora? ¿Cómo opera el conocimiento de las obras anteriores en las expectativas creadas por estos filmes? Y, no menos importante, ¿cómo piensa el cine argentino contemporáneo su propia tradición audiovisual?

Las respuestas a estas preguntas se harán fácilmente visibles en la medida en que se mantenga en el horizonte un presupuesto metodológico clave: no deben atenderse estos trasvases desde un enfoque exclusivamente inmanente. «El texto es el núcleo que debe centrar cada análisis -indica Concepción Cascajosa Virino- pero también son relevantes los apartados de la recepción y de la creación» (2006, p. 12). Más allá de estudiar las continuidades y las diferencias ente una obra fuente y otra subsidiaria, el examen propuesto apunta a asentarse sobre un conocimiento del contexto, de las condiciones de producción (en otras palabras, en su dimensión pragmática) y, asimismo, del modo en que fueron recibidas estas nuevas entregas para poder comprender más acabadamente muchas de las decisiones formales, algunas de las cuales solamente hallan su explicación en aspectos ajenos a la propia carnadura semiótica de las películas.

El presente artículo se organiza alrededor de una hipótesis central: ambas películas instituyen, por vías dispares, un gesto de reconciliación con el pasado como mecanismo para elaborar una perspectiva de cara al presente. En el caso de la dupla Aniceto/Este es el romance... Leonardo Favio revisa su propia trayectoria unificando (por lo tanto, reconciliando) las dos líneas principales de su obra, una primera ligada a la experimentación propia de los nuevos cines y aquella que a posteriori lo volvería reconocido para el gran público, firmemente asentada sobre el deseo de captación masiva mediante el empleo de la cultura popular. Como una suerte de testamento fílmico (Font, 2000), Aniceto se recorta como la quintaescencia de la totalidad de su obra, como una síntesis de dos etapas dispares por las que transitó su cine anterior. En el caso de La patota, Santiago Mitre, un director novel identificado dentro de la camada de los últimos representantes de la renovación cinematográfica iniciada a finales de los noventa, acude a un trabajo firmado por un realizador estrechamente asociado al modelo clásico-industrial (Tinayre) y protagonizado por una de las estrellas más resonantes de esta época de oro (Mirtha Legrand). Mediante esta apelación, la película de Mitre logra tender puentes (una vez más, busca reconciliarse) con una estética en cierto modo contraria a la de su lugar de pertenencia. Considerado como una

\footnotetext{
${ }^{1}$ En España y otros países la película fue exhibida con el título de Paulina, aludiendo al nombre de la protagonista. En función de que se citarán críticas y comentarios provenientes de la prensa argentina se optó por respetar el título original de la cinta.

(C) Ediciones Universidad de Salamanca / CC BY - NC ND Fonseca, Journal of Communication, n. 14, 2017, pp. 113-129
} 
continuación tardía de las rupturas modernizadoras sesentistas ${ }^{2}$, el grupo de pertenencia de Mitre marca una distancia, al igual que aquel Nuevo Cine Argentino al que se lo vincula, con el pasado clásico, llegando a entablar incluso una candente reyerta histórica. En esto radica una de las claves del carácter extraño de la película al ubicarla en paralelo con sus contemporáneas. En otro sentido, las condiciones de producción del remake se decantan también hacia el establecimiento de una apuesta conciliadora. En este proyecto se unieron unos sellos reconocidos, algunos de los cuales detentan un marcado sesgo comercial, como Telefónica Studios -gestor de éxitos arrolladores como El secreto de sus ojos o Relatos salvajes (Damián Szifrón, 2014) - congeniando con los modos de hacer y con la adscripción de este director al «cine anómalo» (Aguilar, 2010, pp. 239-242) situado en las antípodas de las aspiraciones monetarias de aquellas grandes corporaciones que tomaron a su cargo la responsabilidad de financiamiento del film.

\section{ANICETO: RETORNO Y VARIACIÓN}

Existe un consenso crítico prácticamente unívoco que coloca a Leonardo Favio en el centro del podio de los grandes cineastas argentinos. En una encuesta realizada por el Museo del Cine «Pablo Ducrós Hicken» de la Ciudad de Buenos Aires en el año 2000 en la que una gran cantidad de especialistas votó por las cien mejores películas nacionales, su obra, que hasta ese momento contaba solamente con ocho largometrajes, obtuvo nada menos que seis menciones, tres de las cuales se ubicaron entre los primeros diez lugares (Vieytes, 2000). Su dilatada carrera como director, iniciada en 1965 con Crónica de un niño solo, estuvo pautada por momentos de alta productividad -sobre todo entre finales de los sesenta y la primera mitad de la década siguiente- y largos períodos de silencio. Tomando en cuenta estos antecedentes, era esperable que su regreso a la ficción con Aniceto fuese ampliamente celebrado por la prensa y la crítica especializada. La posibilidad de reencontrarse con la obra de un realizador clave y, también para otros, la de ver por primera vez un film suyo en salas comerciales -dado que su último estreno, Gatica, «el mono», databa de 1993- motivó diversas manifestaciones públicas. Además, al tratarse de una propuesta que buscaba asentar sus valores sobre los cimientos de su propio itinerario autoral, sobre el conocimiento y la admiración que este generaba, movilizó cierta necesidad de establecer comparaciones. Los comentarios críticos, y en general la recepción de Aniceto estuvo dominada por el imperativo de recapitulación de los rasgos de su intransferible estilo de cara a la que sería su última creación.

Como en cualquier otra instancia en la que el cine acude a una referencialidad intertextual explícita al momento de configurar sus relatos, la práctica del remake moviliza necesariamente las expectativas del público de un modo específico alrededor de aquello que se le ofrece ante sus ojos. Este no solamente se predispone a juzgar los grados de afinidad que la obra nueva reconoce sobre la precedente; asimismo, también está en condiciones de exigir variaciones, actualizaciones o clarificaciones de contenidos que permitan dirimir una cuota de originalidad del texto fílmico subsidiario con relación a su fuente. Se trata, por tanto, de una inevitable tensión que media entre la valoración de lo ya conocido frente a cierta demanda de la platea de ser interpelada por algo distinto. Andrew Horton define aquello que provoca el remake en los receptores como una negociación. Es, en sus palabras, una transacción tácita que asume la forma de «un acto de equilibrio autoconsciente entre lo familiar y lo nuevo o lo familiar 'transformado'» (Horton y McDougall, 1998, p. 174).

\footnotetext{
${ }^{2}$ Sobre las conexiones entre el Nuevo Cine Argentino histórico y el también bautizado sintomáticamente «Nuevo cine argentino» de los noventa puede consultarse, entre otros textos, el libro de entrevistas compilado por Fernando Martín Peña (2003) y el artículo «Un proyecto inconcluso. Aspectos del cine contemporáneo argentino» de Emilio Bernini (2003).

(C) Ediciones Universidad de Salamanca / CC BY - NC ND Fonseca, Journal of Communication, n. 14, 2017, pp. 113-129
} 
Al igual que lo que acontece con otras prácticas adaptativas, las nuevas versiones de un film promueven la emergencia de una evaluación de tipo contrastivo. Desde la más llana aparición del consabido juego de «reconocer las siete diferencias» hasta reflexiones más refinadas articuladas en torno a la autonomía formal de cada obra, la mayor parte tiende a ampararse en edificar comparaciones sobre las que se basa la evaluación de los resultados. Esta cuestión aparece motivada fundamentalmente por un pensamiento unidireccional sobre lo que implica un remake. Una relación equívoca que presupone «un movimiento que va de la autenticidad a la imitación, de la superioridad identitaria de la original a la semejanza degradada de la copia» (Verevis, 2006, p. 58).

Si la negociación entre lo conocido y lo novedoso interviene como una prerrogativa del examen de un remake ¿qué sucede en un caso como el de Aniceto, en el cual es el propio director quien toma a su cargo el traslado de un film que lleva su firma? ¿Cómo se organiza esta exigencia de innovación, enfrentada inevitablemente al goce generado por la identificación de unas marcas estilísticas que permiten constatar la presencia de un autor cinematográfico?

El primer tramo de su producción, precisamente aquel en el cual se sitúa El romance del Aniceto y la Francisca junto a los restantes filmes de los sesenta -Crónica de un niño solo y El dependiente (1969)-, estuvo signado por una ligazón estrecha con los parámetros del cine moderno contemporáneo. Su ascetismo formal, el uso del blanco y negro, las construcciones temáticas desarrolladas parecen renegar a primera vista de la cualidad de gran espectáculo predominante en sus trabajos posteriores. La maximización del silencio, la total ausencia de ampulosidad en la articulación de la puesta en escena y el armado de una narración ajena en todo sentido a los modos convencionales trazan reminiscencias claras con el aire de los tiempos, particularmente con la figura de Robert Bresson y con otros realizadores de la modernidad. David Oubiña y Gonzalo Aguilar señalan que en estas películas «el contraste que surge del salto entre los planos y las imágenes provoca la separación de sus elementos narrativos». Porque, en definitiva, «la imagen no está encadenada en la imagen siguiente, al menos no en términos de una acción continua» (1993, p. 46). Con dichos recursos, Favio se convirtió en un cineasta avalado por los sectores de la intelectualidad de avanzada, pero desconocido o por lo menos no admirado masivamente por el gran público. Con posterioridad a estas experiencias iniciales, el director efectuó un viraje radical. Su abierta afinidad con la causa peronista pero también el agotamiento de las innovaciones propiciadas por los nuevos cines, coadyuvaron a que su estilo mutara hacia una búsqueda de adhesión masiva. Como recordaría años más tarde: «A mi me subyugaba el hecho de que me reconociera la crítica, pero luego me propuse hacer lo que siempre entendí que debía hacer: un cine nacional y popular» (en Peña, 2003, p. 97). Y para lograrlo, Favio entendió que debía decantarse por la desmesura, magnificar el entretenimiento y, en definitiva, brindarle a un espectador no iniciado aquello que este encontraba fácilmente en otras producciones culturales. Para Oubiña y Aguilar «el cambio fundamental estaría en los materiales y en el público al que se dirigiría la nueva película. La preocupación formal de sus anteriores films se mantendría, aunque transformada en función de estas nuevas incorporaciones» (1993, pp. 79-80). Iniciada con el estreno de Juan Moreira (1971) esta segunda etapa basaría su efectividad en la ligazón con las tradiciones populares -desde la gauchesca al radioteatro o la comedia familiar-, en el uso del color, de las canciones y, asimismo, en un estilo barroco y en cierto modo kitsch en nada temeroso de recurrir a una desembozada artificiosidad para tornarse visible.

Según se mencionó al principio, Aniceto opera a la manera de un marco en el que se concreta la unión de esos dos momentos en cierto modo antitéticos. Podría verse esta película como un estado de cuentas, un balance provisto por un cineasta aquejado de una larga enfermedad que busca conciliar las diversas corrientes de su propia obra. Anticipando una lectura sobre el film, Favio admite la idea de 
síntesis, de condensación de motivos con vistas a la formulación de una propuesta en la que se conjugan, en simultáneo, la variación y la repetición:

Si bien vuelvo a un personaje anterior, con su gallo de riña y sus dos mujeres, esa tragedia a la que no parecen poder escapar, y también regreso a Luján de Cuyo dónde me crié y que me visita en mis desvelos; se puede ver a Aniceto como algo intermedio o como una síntesis, ya que la considero mi película más completa, posee una estética más cercana a mis últimas películas con una historia y personajes de la primera etapa. Es la obra de mi madurez. Aquellos largos silencios con cantos de la naturaleza, aquí se convierten en un gran espectáculo sonoro y enorme juego de color, como si fueran cuadros para cada escena. (Farina, 2008).

Favio evidencia la voluntad de inscribir el relato bajo la lógica del retorno desde los primeros parlamentos. Inmediatamente después de los títulos de crédito se escucha en un espacio indeterminado su propia voz. A la manera de la apertura de un cuento o de un mito, el director irrumpe en la banda sonora anunciando: «de mil historias que rondan mis insomnios, hoy quise rescatar la de Aniceto». Desde la autoconsciencia narrativa aportada por el reconocimiento de su pronunciación inconfundible (y de su reconocido lugar de autor), Favio instala ya en los minutos iniciales una marcación que sitúa a su película con relación a una acción pasada. El carácter mítico que adopta el relato en el remake cumple una función idéntica a la que detentaba el largo título de la primera: menguar la incertidumbre en el público. Más allá de su condición evocativa, un inicio de esta clase apunta a delimitar un territorio personal, la existencia de un acervo rescatado de las profundidades del imaginario personal de un cineasta maduro. El acto de volver a ofrecerlo surge, por lo tanto, como la respuesta a las demandas de un público cautivo. La frase se recorta sobre el fondo de las imágenes del reflejo que el agua produce, mostrando al mismo tiempo una coloración vibrante y una nitidez escasa, casi abstracta. Mientras las palabras definen una orientación de aquello que se verá a continuación como algo ya acontecido, esta primera escena brinda pistas sobre el tono. La idea de recuerdo aparece desde el inicio poniendo en primer plano su carácter borroso, oscilante. Abismando la representación, la fluidez del agua niega la posibilidad de configurar una repetición exacta, mostrando, por el contrario, una inclinación deliberada hacia las potencialidades de su transformación.

A grandes rasgos, la nueva entrega recobra las principales líneas narrativas de la primera. Una vez más, el relato opta por enfocarse en un número reducido de personajes, sobre un conflicto central ocasionado por la aparición del triangulo amoroso. En ambos filmes, el trayecto narrativo cumple un periplo idéntico: nacimiento de la relación entre el Aniceto y la Francisca, aparición de la Lucía, ruptura, comienzo de la tristeza y desenlace. Nuevamente, al igual que sucede en el resto de la filmografía del director, se repite el destino trágico del protagonista y la construcción de personajes sin mayores atributos, casi como si se tratara de los roles de un misterio medieval en el cual importa más el grado de su tipificación -el macho, la mujer sufrida, la tercera en discordia- que sus psicologías individuales o el detallismo en su definición social.

El cambio más evidente en la operación de reescritura de la propia obra se produce en el trabajo sobre la puesta en escena. Mientras El romance del Aniceto y la Francisca organiza sus materiales sobre la base de la minimización de elementos, sobre la reducción de la trama a sus rasgos fundamentales mediante unos diálogos y situaciones pautados por el silencio y la inmovilidad del encuadre, el remake opta por la desmesura visual y sonora. El director convierte la historia en un ballet filmado dentro de 
un estudio ostensiblemente artificial. En consonancia, las acciones se despliegan en el espacio seguidas por largos travellings en plano secuencia.

En efecto, si en la primera los vacíos narrativos y las elipsis marcadas pretenden obturar la visión de una totalidad, eludiendo la narrativización de varios momentos clave, en Aniceto los cuerpos de los actores-bailarines completan estos hiatos a partir de la exhibición de unos desplazamientos que determinan las emociones y los vínculos entre los personajes. Sin embargo, como ocurre en el resto de la filmografía del director, en este caso el uso del ballet y la puesta en evidencia consciente del irrealismo del decorado persiguen el establecimiento de un modo de distancia-afección (Oubiña y Aguilar, 1993) característico de su poética individual. Entonces, pese a la aparente disparidad en las elecciones estilísticas, los filmes permanecen unidos por los efectos que sus estrategias formales buscan generar en los espectadores. Refiriéndose a su pasaje de su etapa inicial (asociada a la modernidad de los «nuevos cines») a la segunda, interesada en captar la atención popular, Favio argumentaba: «para que una película sea convocante tiene que tener eso que te entretiene, que te divierte, que es espectacular» (en Schettini, 1995, p. 123). La inclusión del ballet sobre el fondo de una banda sonora capaz de mezclar a Vivaldi y Chopin con tangos y cumbias -otro gesto de reconciliación, en este caso entre la alta cultura y la cultura popular- obtiene un regodeo en el virtuosismo que, lejos de pensarse como elitista, es ofrecido al gran público sin intermediaciones de ninguna clase.

Si bien la narración es replicada prácticamente punto por punto, existe una única instancia que se omite deliberadamente. Se trata de una escena clave, aquella en la que se instaura el triángulo amoroso a partir del cruce furtivo de las miradas del Aniceto con la Lucía. En la cinta de los sesenta, la instancia que propicia el encuentro entre los tres quedaba encuadrada al interior de una representación teatral montada por un grupo trashumante a la que los protagonistas asisten. Claramente distanciado de cualquier atisbo de modernidad, el espectáculo que los personajes presencian, acompañados por el pueblo en su conjunto, reniega (o desconoce) toda forma de realismo hundiéndose en los esquematismos visuales y en unos antagonismos directos. Según Favio, la secuencia fue un homenaje a la compañía de teatro popular encabezada por su madre y su hermano: «fue toda improvisada. La hacíamos con los amigos. Era lindo. El malo era malo, malo, malo. Y el bueno era bueno, bueno. Y ahí está la frase 'Un ángel hizo justicia', eso era parte de la inocencia del espectáculo» (en Schettini, 1995, p. 102). Buscando reivindicar lo primitivo, el gusto por lo popular como estrategia legítima de representación, la forma en que este momento teatral aparece filmado hace sobresalir la escenografía de telón pintado, las actuaciones declamatorias y los trucajes visibles para el público. Incluso en los títulos de crédito, los actores de la puesta enmarcada son mencionados por los personajes arquetípicos que componen en la escena: «la madre buena», «el estanciero cruel», «la bruja», «el galán». Adhiriendo a dicha modalidad de inscripción de la teatralidad, la incorporación de la obra en El romance del Aniceto y la Francisca remite, debido a la continuidad en el plano, a la ubicación de la cámara -de manera frontal, en un plano general que adopta el lugar del espectador ideal de un escenario de caja a la italiana- al cine de los orígenes, particularmente a la estética popularizada por las películas de Méliès. Contrastando con el carácter arcaico predominante en la filmación del juego de los comediantes, el contraplano que le sucede, aquel en el que aparecen los personajes distribuidos entre el público de la función, se organiza alrededor de un tipo de emplazamiento espacio-temporal antitético: apelando a la profundidad de campo y al silencio se narra la infatuación amorosa entre el Aniceto y la Lucía. En otras palabras, la construcción de esta escena marca el «comienzo de la tristeza» a partir de unos pocos gestos mínimos que dejan atrás la teatralidad para retomar un tipo de construcción espacial desde los recursos cinematográficos. Tal como indicaba Jacques Aumont sobre algunos directores de la modernidad -Bergman y Buñuel, entre ellos- Favio elabora con esta cita una puesta en escena fílmica que «conjuga evidentemente el recuerdo 
de la teatralidad primitiva con la consciencia de la libertad del punto de vista, del ángulo, de la distancia» (Aumont, 2013, p. 35).

La secuencia del teatro, un homenaje simultáneo a la tradición cultural local y al cine de principios de siglo, queda completamente eludida en Aniceto. Sin embargo, no se trata de un olvido o de una negación. Por el contrario, la elección de no replicar esta instancia parte del hecho de haber reubicado sus elementos en una posición privilegiada, integrándolos al magma común de su construcción fílmica. Favio afirmaba sobre el modo en que este aspecto pasó a ocupar el lugar de un leitmotiv visual, volviendo evidente la relación intrínseca de aquel momento teatral del film de los sesenta con respecto a su relectura contemporánea: «en El romance... aparecía una 'rascada' sobre un escenario en el que un angelito era izado con sogas a la vista, pero en Aniceto cumplí mi sueño de hacer una película como las de ese pionero de la fantasía cinematográfica que fue Georges Méliès, y esta vez me permití volar en esa dirección» (Farina, 2008). Bajo esta lógica, los escenarios de cartón-piedra, los telones pintados, la explícita condición de plató del espacio y, sobre todo, los emplazamientos de la cámara, situada a una distancia considerable de las acciones, funcionan de manera coherente con esta búsqueda.

Mediante este cambio significativo del relato de base, el cineasta pone al descubierto el sentido global que asume su retorno. Configura un linaje, situado tanto en los orígenes del cine como espectáculo, pero también en los inicios del teatro popular para encarar la revisión de su propia historia como creador audiovisual. Para volver, según lo enunciado por Ana Amado en su estudio sobre el documental Perón, sinfonía de un sentimiento (Leonardo Favio, 1999), «a ese pasado con relatos de afección, con el lenguaje intemporal, pero apasionado del mito» (2009, p. 98).

\section{LA PATOTA: DEL PERDÓN A LA CONVICCIÓN}

La película formulada a partir de la pieza de Daniel Tinayre resulta un caso aún más extraño que la reescritura de El Aniceto y la Francisca. En tanto la última puede ser vista como una típica operación revisionista que un autor legitimado acomete sobre su propia caligrafía fílmica, similar a otros casos célebres como podrían ser las reversiones de Leo McCarey, Howard Hawks o Alfred Hitchcock sobre sus filmes anteriores, La patota de Santiago Mitre implica una distancia mayor entre la obra fuente y el texto fílmico subsidiario. No se trata solamente del hecho de que aquí haya sido un nuevo cineasta el responsable de instalar su propia perspectiva alrededor de una obra previa, sino también del modo en que se originó esta relación y de las implicancias actuales buscadas al momento de reconfigurar los problemas abordados por un relato decididamente anclado en otro momento histórico.

El proyecto partió de un encargo que Áxel Kuschevatsky, principal referente local de la corporación multimedial Telefónica Studios, junto al productor Nacho Viale (nieto de Daniel Tinayre y Mirtha Legrand) encomendaron a Mitre. En principio, una de las razones esgrimidas para la recuperación del film de los sesenta fue la de rendir un homenaje al director de la original, al cumplirse en 2014 veinte años de su fallecimiento. Con independencia de este afán celebratorio, complementado también con el reestreno de la copia remasterizada del que fuera su último largometraje, La Mary (Daniel Tinayre, 1974), la nueva versión de La patota brindó la ocasión de revisitar desde un enfoque novedoso una película clásica poco vista últimamente que, no obstante, conservaba por el tema tratado visos de actualidad. Según las declaraciones de sus mentores este seguía abriendo una discusión sobre conflictos que tenían un claro eco en situaciones sociales contemporáneas.

Santiago Mitre, por su parte, venía de estrenar su ópera prima en solitario, El estudiante (2011), bajo las premisas del «cine anómalo»: costos reducidos, sin apoyo oficial o de grandes empresas, distribución acotada y circulación en espacios no tradicionales. Singularmente, esta primera experiencia alcanzó un relativo éxito de taquilla, teniendo en cuenta las estructurales limitaciones comerciales 
enumeradas. Complementado por su reconocida experiencia como guionista de algunos filmes resonantes -Leonera y Carancho (Pablo Trapero, 2008 y 2010, respectivamente)- la repercusión comercial de El estudiante movilizó el interés de los productores al momento de convocarlo para elaborar una reescritura en todo sentido libre de la original.

El rol del director dentro del proceso de trasvase cumplió una función determinante. La pericia narrativa de Mitre y su lugar de cineasta «revelación» funcionaron como un efectivo aliciente que permitió concretar el acercamiento al público basándose en su prestigio y en el carácter ciertamente innovador que acarreaba recuperar una historia protagonizada originalmente por una diva del cine clásico como Mirtha Legrand, aún activa como conductora televisiva y con una notable presencia pública en los medios. Adherido a ambas cuestiones, el eje a partir del cual se estructura el relato -la violación sufrida por la protagonista perpetrada por la «patota» del título- en el marco de una creciente agudización de manifestaciones sociales en contra de la violencia machista y los femicidios, aparece como un dato externo orientador de algunas claves de lectura de la película. Justamente el 3 de junio de 2015, tan solo unos pocos días antes del estreno comercial de La patota en Argentina (18/06), se realizó en distintos puntos del país la protesta conocida como \#Niunamenos, que movilizó a amplios sectores de la sociedad. Esta coincidencia (dado que el film fue concluido con antelación a estos sucesos y presentado exitosamente en mayo en el festival de Cannes, donde obtuvo el premio principal de la Semana de la crítica y el galardón otorgado por FIPRESCI) fue subrayada por algunos comentarios de la prensa (entre otros, Ajmat, 2015; Soler, 2015). La mención a la coyuntura sociopolítica fue inevitable toda vez que se buscó resaltar la actualidad de los temas desplegados en la trama.

En tanto existió desde el inicio un reconocimiento manifiesto de que se trataba de un remake, la modalidad de trabajo sobre la obra original se planteó con una total libertad para profundizar en las distancias o en otros temas que no fueron esbozados en aquella primera película. El propio director declaró no haberse sentido constreñido por una idea de respeto o de continuidad obligada entre su proyecto y su antecesora: «a partir de una primera visión, ya aparecieron nuestras propias ideas de adaptación. Después, no hubo necesidad de consultarla. Fue una película que se configuró como algo nuevo muy rápido. Hubo que adaptar el personaje y el contexto a la actualidad» (Diz y Domínguez, 2015). La voluntad de abandonar rápidamente las marcas de la original al intentar encaminar otras búsquedas no fue una acción privativa del director. Según declaraciones de Dolores Fonzi, la actriz principal, Santiago Mitre puso como condicionamiento para su labor creativa que esta compusiera su personaje sin tener en cuenta el film de Tinayre, obra que, hasta el momento en que se presentó públicamente esta segunda versión, no había visto. Incluso Nacho Viale, el productor más cercano afectivamente al trabajo de sus abuelos, enfatizó que, más que ante una repetición, el público se encontraría ante algo distinto, completamente independiente del anterior.

La patota de Tinayre está organizada desde el principio como un alegato católico en favor del perdón. El film se inicia in media res, en una escena en la que uno de los jóvenes (Walter Vidarte) corre hacia el encuentro de sus compañeros. Los sonidos de un tren en marcha y de una sirena de ambulancia establecen un complemento a las primeras líneas de diálogo. Esta situación coloca a los espectadores ante la presencia elusiva de un accidente que ya ha tenido lugar. A continuación de los títulos de crédito, impresos sobre el fondo de un edificio de un barrio periférico, se sucede un cartel. Se trata de una cita al Evangelio según San Mateo en el que se lee la frase «Señor ¿Cuántas veces deberé perdonar a mi hermano cuando pecare contra mí? ¿Hasta siete veces? Respondiole Jesús: No te digo yo hasta siete veces, sino hasta setenta veces siete, o cuantas te ofendiere».

Según los planteamientos de Santos Zunzunegui (1996) los prólogos y epílogos de los filmes resultan indicadores fundamentales encargados de enmarcar las principales líneas o, en otros términos, 
los basamentos articulados por las películas. Por su condición de «portadores de una explícita dimensión emblemática» (Zunzunegui, 1996, p. 127), dichas instancias narrativas condensan significaciones destinadas a orientar la interpretación de la totalidad. En esos primeros minutos, la cinta de los sesenta, traza un abanico en el que se complementa la situación del grupo de jóvenes -la patota en cuestión- con la violencia de los sonidos que ponen sobre aviso a los espectadores acerca del tono dramático, dejando traslucir, con ayuda del claroscuro de la fotografía, cierto carácter ominoso del relato. Como correlato de los elementos desplegados en la banda visual y sonora, el fragmento bíblico, debido a su capacidad para tomar el lugar de una consciente homilía, deviene en aglutinador que condensa los aspectos que se verán a continuación y que ya fueron preanunciados en los tramos iniciales. Lo que vendrá a posteriori será, en consecuencia, el desarrollo de esta idea central. A la manera de un largo flashback originado en ese punto cero narrativo motivado por el accidente, se expondrá la idea de perdón, de reconciliación por parte de ese sujeto santificado representado por Paulina Vidal.

La heroína interpretada por Mirtha Legrand se asienta sobre la idea de beatificación de la víctima. Abiertamente delineadas como una reificación del mandato cristiano de poner la otra mejilla frente a los agresores, sus acciones dentro del relato operan a partir de una lógica basada en la comprensión del otro y en el abandono de la propia comodidad. Paulina es una chica joven, recientemente egresada como profesora de filosofía con el mejor promedio de su promoción. Frente a la perspectiva de una vida burguesa (expuesta en la escena inicial de la fiesta de graduación), resguardada por su bienestar económico asegurado, por un novio formal con el cual planea casarse, el personaje opta por dar clases en una escuela nocturna para adultos en un barrio marginal, a la que asisten los hombres que terminarán violándola por error, confundiéndola con otra mujer. A partir de esta situación, mostrada apenas pasados veinte minutos del inicio, se produce un punto crucial de exposición de su comportamiento. A partir de este momento todos los pliegues de la trama se orientan a profundizar en la exposición de su carácter benévolo. En esta instancia se inicia el periplo dramático, basado en una suerte de viacrucis organizado en torno a la lógica del perdón. A través de un despliegue narrativo asociado al melodrama con tintes sociales, La patota sesentista propone, como un subtexto colocado en paralelo a su trama principal, una postura inclinada hacia la reconciliación de las clases. La fe insobornable que define el comportamiento del personaje justifica su accionar al interior del relato. De esta cualidad se desprende su decisión de no inculpar a sus alumnos cuando ya posee pruebas contundentes, de proseguir con el embarazo producto de la agresión sexual y, finalmente, de renunciar a la propia búsqueda de la felicidad. Si, según los preceptos católicos, el abandono de las ventajas materiales configura un primer estadio en el pasaje a la santidad, la violación aparece como una de las múltiples dificultades que deberá sortear Paulina para alcanzar la gracia divina.

La versión contemporánea niega la concepción religiosa de la primera, trasmutándola en un dilema ético de carácter netamente laico. Tomando distancia de todo vestigio melodramático, la puesta en escena configura desde el principio un anclaje en la estética modernista. La escena inicial está organizada como un largo plano secuencia de varios minutos de duración. Allí Paulina (Dolores Fonzi) debate encarnizadamente con su padre (Oscar Martínez). Más allá de esbozar la disparidad en las posiciones político-ideológicas de ambos, articuladas alrededor del papel que un intelectual debe cumplir con relación a los sectores oprimidos, la opción por construir una toma en continuidad supone una afirmación en la potencialidad del realismo cinemático. Más que un discurso unívoco subrayado por el mandato bíblico, la apertura muestra en este caso lo irresoluble de la situación, lograda a través del desempeño de los actores y gracias, sobre todo, al constante crescendo dramático de la discusión filmada en continuidad. En esta primera escena, al igual que en el film de Tinayre, quedan trazados tanto las líneas centrales del relato (la mujer imponiendo sus convicciones enfrentada a los argumentos 
de su entorno) como el estilo adoptada por la narración, construido alrededor de un sujeto único que en la mayor parte del tiempo que dura esta toma dirige sus palabras a un espacio situado en el fuera de campo. Dentro de la transformación en los sentidos de las acciones, resulta capital el hecho de que se produzca un giro en la profesión de la protagonista: de profesora de filosofía, la nueva Paulina pasa a ocupar el rol de abogada que impartirá clases en un plan de difusión de derechos a comunidades del interior profundo de Argentina. Entonces, si en el primer caso todavía puede pensarse en un idealismo teñido de fe religiosa explícita, en la nueva película los dilemas quedarán asociados a un racionalismo evidente y al planteo de cuestiones alrededor del papel de la justicia.

La conversión de lo religioso a lo laico provoca que algunas situaciones dramáticas parezcan poco atemperadas en el remake. En la primera Paulina, la decisión de no abortar aparece motivada por sus convicciones católicas (independientemente de que se trate de un film propio de un modelo narrativo en el que estos temas están vedados). En 2015 la continuación de este aspecto se torna incomprensible, solo justificable en un personaje aferrado a su propia terquedad ${ }^{3}$, a costas de terminar rompiendo relaciones con el resto de las personas que la rodean (su novio, su compañera de trabajo). Por otro lado, la nueva película se permite ahondar en unas cuestiones que la original no atendía. La exposición de la condición humillante a la que se ve sometida la protagonista al efectuar la denuncia policial o el sometimiento del propio cuerpo a la ley y a los médicos conforman, por el modo descarnado en que son mostrados, unos rasgos innovadores. En ese conjunto de escenas que ocupan un lugar importante, el film de Mitre abraza un sentido político atento a traducir fílmicamente las discusiones de género.

A diferencia de 1960, la película coloca a la violación no solamente en el lugar de una acción violenta, sino que también pone en primer plano el carácter de opresión estructural a la mujer que este delito conlleva, mostrando a Paulina en una sucesión de escenas que replican la misma idea desde múltiples perspectivas. El enfrentamiento solitario a un entorno completamente hostil vuelve explícita la convicción del personaje, anudada fundamentalmente a la certeza de la posesión sobre las vicisitudes de su propio cuerpo.

Otro cambio significativo parte de la relocalización de la trama en un espacio totalmente distinto. Si el film de Tinayre configuraba su dilema interclasista a través de la mostración de la distancia entre la casa burguesa de la heroína y su lugar de trabajo en la periferia de la ciudad, en esta revisión se optó por trasladar las acciones al norte argentino, en una zona rural de la provincia de Misiones, limítrofe con Brasil y Paraguay. Esta modificación, según Santiago Mitre, partió de la necesidad de eludir un contexto geográfico que «hoy está cristalizado en el cine argentino y en la televisión; que se ha convertido en un territorio demasiado filmado en ficciones y en muchos documentales» (Kairuz, 2015). Más allá de no pretender tomar partido por unos tópicos ya transitados por otros registros audiovisuales, el viraje impone una transformación obligatoria asociada al modo de configuración escénil grupo que ataca a Paulina. Sus integrantes no son ya sujetos urbanos, pobres, pero con todo cercanos a la protagonista. En esta nueva visión, la patota está conformada por indígenas. Independientemente de su miseria estructural, estos carecen de nociones básicas como el derecho y la justicia, según lo que plantea el propio film en las escenas en la escuela. Los «otros» a los que se enfrenta la mujer son percibidos en esta película como pura alteridad, dejando traslucir que ya no hay ningún punto de conexión posible entre las partes en cuestión. En consecuencia, mientras la primera película finalizaba con la frase de los jóvenes refiriéndose a la «lección» impartida por la profesora, en esta visión ya no queda resquicio para un aprendizaje o para la posibilidad de reconciliación a través de un discurso moralizante.

\footnotetext{
${ }^{3}$ En uno de los primeros comentarios acerca de la película, el crítico de Libération definió el trabajo de la actriz protagónica como «una terquedad que la excelente Dolores Fonzi encarna a través de su mirada tensa» (Gester, 2015).

(C) Ediciones Universidad de Salamanca / CC BY - NC ND Fonseca, Journal of Communication, n. 14, 2017, pp. 113-129
} 
Sobre todo, la crítica contemporánea leyó la película de Tinayre a partir de un planteo metacinematográfico en el cual confrontaban dos épocas del cine en un momento de transición. Mirtha Legrand, referente indiscutible del modelo clásico, era violentada por unos actores ignotos pertenecientes a la generación surgida con el cine moderno de los sesenta. Walter Vidarte, Alberto Argibay y Luis Medina Castro, los integrantes de la patota, fueron algunos de los rostros visibles que protagonizaron los cambios propiciados a inicios de esa década. En la nueva versión se optó, en cambio, por una interacción entre actores profesionales (Fonzi, Martínez, Esteban Lamothe, Laura López Moyano) e intérpretes eventuales que aportaron una carnadura verídica a las acciones desplegadas. Según el director:

Teníamos que preguntarnos quiénes son estos pibes hoy (...) Por eso buscamos chicos que no cargaran con un texto previo de ficción, como sí lo tenían Vidarte o Argibay. De los cinco de la patota, sólo dos traían alguna experiencia, algún entrenamiento en un taller barrial, pero trabajé con ellos igual que con los profesionales: memorizaron el texto, siguieron las marcaciones, repitieron tomas; nada de improvisaciones» (Kairuz, 2015).

El problema principal, debido a esta vocación de toma de distancia de los tópicos anteriores, estriba en que aquí la patota aparece como un grupo sin otra entidad que la de ser violentos. La película muestra desde el principio la desconexión entre la protagonista y los otros. Cuando Paulina da su primera clase se expone este grado de separación entre ambos sectores. Frente a las preguntas de la profesora, los alumnos responden con un silencio total o bien optan por hablar en guaraní, exhibiendo una distancia inexpugnable. En un ejercicio de imaginación los alumnos dejan en claro que es la mujer quien pone las reglas porque es caté (fina, distinguida. En otras palabras: perteneciente a otra clase). Las diferentas instancias muestran de manera crítica el impulso mesiánico de unos proyectos sociales que buscan instruir a los dominados en «participación política», exhibiendo la imposibilidad de reconciliación entre los diversos sectores.

La exposición de ese "pueblo» a la manera de un fondo sobre el cual se recorta una figura única posee derivaciones en el modo en que este sujeto colectivo es construido tanto narrativa como figurativamente en la pantalla. Según Didi-Huberman:

No basta, pues, con que los pueblos sean expuestos en general: es preciso además preguntarse en cada caso si la forma de esa exposición -encuadre, montaje, ritmo, narración, etc.- los encierra (es decir, los aliena y, a fin de cuentas, los expone a desaparecer) o bien los desenclaustra (los libera al exponerlos a comparecer, y los grafica así con un poder propio de aparición). (2014, p.150)

El film de Mitre construye una franca oposición desde el primer momento en que se muestra a los jóvenes. La llegada de la profesora a la localidad en un automóvil que circula por un camino de tierra, es completada por un contraplano en el que aparece, en la cima de un pequeño cerro, un grupo de hombres mirando la circulación del vehículo. La elección de este encuadre, que recuerda a la disposición de los cuerpos de los indígenas de los wésterns clásicos (Duarte, 2015), traza desde el inicio una configuración que separa la civilización de la barbarie, instalando desde el principio la contradicción entre la ley social y la ley natural. A partir del uso de estas imágenes, que remiten ineludiblemente a un conflicto aporético, se pone de manifiesto visualmente la imposibilidad de resolución de las contradicciones sociales. 
Conforme avanza el relato, el pueblo pierde espesor hasta desaparecer completamente. Si en un principio se erigía en un fondo homogéneo o indivisible (inidentificable) sobre el cual se perfilaban mejor las características del personaje principal, con el correr de los minutos va perdiendo su lugar al interior de la puesta en escena debido a que la narración se sumerge con mayor énfasis en la subjetividad de Paulina. En este punto radica la mayor diferencia entre el film original y el remake. En La patota de 1960 los jóvenes poseían una voz propia, podían determinarse comportamientos individuales y se accedía también a su propio proceso de conversión y arrepentimiento. En 2015, por el contrario, prácticamente carecen de rasgos que los singularice, salvo su identificación como parte de un grupo carente de otras cualidades que no sean la miseria y la violencia congénita.

En este punto se comprenden mejor las razones por las que La patota fue presentada en otros países simplemente apelando a un nombre: Paulina. Aun cuando se trata de un término intraducible a otras lenguas, el cambio acentúa aquello que la narración despliega en su totalidad: una construcción articulada alrededor de un personaje en soledad que domina el relato mientras el resto aparece bajo la forma de unos obstáculos con los cuales se dirimen sus decisiones éticas. En Argentina, solamente a título de referir un lazo de familia con su antecesora de los sesenta, debido a que este título sí podía resonar en el imaginario de los espectadores, se conservó su denominación original.

En la opción de concentrar el foco de interés en los dilemas internos de una mujer, el film de Mitre abandona completamente las vicisitudes del relato clásico para abrazar la opción por la modernidad. Según Serge Daney (2000), el cine moderno cambia un tipo de punto de vista articulado alrededor de las certezas masculinas por el cine de la alteridad, en el que las mujeres se interrogan por su propia identidad, por su deseo. El director de La patota afirmó en repetidas ocasiones que una de las fuentes de inspiración para reescribir la trama y pensar las elecciones de puesta en escena fue Europa 51 (Roberto Rossellini, 1952). En esa pieza clave del relato moderno, Ingrid Bergman abandona su vida lujosa luego de un episodio traumático para vincularse con el otro lado de la sociedad italiana de la posguerra. Como recuerda José Luis Guarner en su estudio sobre la película, en la escena de los exámenes médicos a los que se somete a la protagonista para observar su estado mental, tanto el cine como los instrumentos científicos se demuestran ineficaces para acceder a los estratos profundos del personaje: «si la cámara no puede llegar al secreto que se oculta detrás de un rostro (...), el mecanismo de la ciencia es incapaz de discernir también un proceso de naturaleza moralı (Guarner, 2006: 73). Paulina, al igual que Irene en el film de Rossellini, afirma enfáticamente «no estoy loca». Pero más allá de la coincidencia o de la cita deliberada, ambos se acercan en su configuración visual. La cámara de Santiago Mitre busca ahondar en el interrogante sobre el deseo femenino inexplicable para el resto de los hombres. El novio y el padre -fundamentalmente este último- no logran comprender las motivaciones de la protagonista. La organización de los encuadres se enfoca recurrentemente en el rostro y los movimientos de Dolores Fonzi, rescatando un trabajo en el cual lo que prima es la incertidumbre de los gestos. Ella misma parece desconocer las causas que la impulsan a actuar de esa manera, exculpando a sus agresores y decidiéndose a tener el hijo producto de la violación. La sucesión de imágenes del film se mueve dentro de este imperativo infructuoso por determinar las intenciones profundas del personaje. Más que una respuesta, los tramos finales exponen la continuación indefinida del interrogante, maximizado en el último plano de la película en la cual Paulina camina con rumbo incierto. Entonces, mientras la versión clásica concluye con la santificación de la heroína una vez atravesado su martirio, en la versión actual no hay un desenlace tranquilizador posible, dado que el cierre busca mostrar como única verdad la convicción irrevocable de la mujer. 


\section{CONCLUSIONES}

Al describir la situación de la escena musical actual, Simon Reynolds sostiene que «los 2000 estuvieron dominados por el prefijo 're': revivals, reediciones, remakes, reescenificaciones». Se trata, en suma, de lo que el crítico agrupa bajo un denominador común, articulado en torno a una «retrospección interminable» (2012, p. 12. Resaltado en el original). Amparada en la idea de fin de la historia y en los sucesivos «post» que abundan en el panorama de la crítica y la investigación actuales, la reactivación de textos anteriores se perfila como un síntoma de los tiempos. En una época que ha vislumbrado cómo han «desaparecido el sentido del pasado como carga, sea como pesadilla de tradiciones represivas o como depósito de sueños frustrados, y la elevada expectación hacia el futuro, como cataclismo o transfiguración potenciales, que habían caracterizado al arte moderno» (Anderson, 2016, p. 62) el remake parece alimentar cierta ilusión de eterno presente. Aun celebrando con nostalgia un momento anterior, esta opción no deja de plantearse desde un ahora capaz de declinar todos los tiempos posibles en uno solo.

A lo largo del trabajo se examinaron dos filmes que, si bien responden a esta noción de recuperación del pasado, abordan el problema desde unas visiones disidentes. Los proyectos de La patota y Aniceto no partieron de la idea de reciclar éxitos recientes para colocarlos en unos marcos novedosos o de utilizar lo festivo como principio de exhumación. Con independencia de que el primero haya sido pensado originalmente como una suerte de conmemoración por el aniversario de la muerte de una figura señera del cine clásico y que en Aniceto puede admitirse cierta autocelebración testamentaria pergeñada por el propio director-autor, no son textos cuya existencia se presente como carente de una necesaria revisión sobre el tiempo transcurrido.

Favio y Mitre emprenden unas acciones idénticas basándose paradójicamente en unos mecanismos contrarios. En Aniceto, la relectura se origina en el deseo de formular una síntesis, aquella que permite otorgar una nueva configuración a un texto planteado desde el ascetismo realista basándose para ello en la espectacularidad desmesurada de la danza, en la reconocida artificiosidad de los espacios y en la condición mítica de su propio relato de base. Mitre opta, en cambio, por el camino inverso. Su reinterpretación de La patota se basa en el desmontaje de los aspectos clásicos característicos del film original -apelación al melodrama, defensa de los valores tradicionales de la familia y la religióntrocándolos por la vía de una indagación típicamente moderna, aquella preocupada por dilucidar las aristas del deseo femenino. Con todo, ambos directores comparten una mirada conciliadora con el pasado que, a través de estas películas, pretende barrer con un discurso historiográfico demasiado afincado en la conformación de bloques estancos, de períodos inamovibles.

Ninguno de los dos, por otra parte, busca con sus películas repetir o concretar una vana reivindicación de la tradición que eluda la necesidad de una puesta a punto, de una reconfiguración de sus ejes problemáticos. Como escribió Borges en su «Pierre Menard, autor del Quijote», un texto clave para entender las operaciones emprendidas en cualquier remake:

Componer el Quijote a principios del siglo diecisiete era una empresa razonable, necesaria, acaso fatal; a principios del veinte, es casi imposible. No en vano han transcurrido trescientos años, cargados de complejísimos hechos. Entre ellos, para mencionar uno solo: el mismo Quijote. (Borges, 2006, p. 448).

No transcurrieron tres siglos, sino solamente un poco más de cuatro décadas entre La patota, El romance del Aniceto y la francisca y sus respectivos rescates en el marco del cine contemporáneo. Sin embargo, el universo de las ficciones, las condiciones de producción y, asimismo, el conocimiento de los espectadores que las consumen han sido modificados de una forma abismal. Con todo, estos trabajos 
de reescritura debieron rendir cuentas con sus propios Quijotes. Pese a la distancia, estos remakes tuvieron que dibujarse sobre el fondo de la todavía apreciable existencia de las versiones originales, cada vez más activas debido a la difusión de los medios digitales y a la disponibilidad que estos suponen al momento de visitarlas. En este sentido, no resulta casual que la mayor parte de las críticas abunden en el establecimiento de comparaciones.

La fuerza de todo retorno radica en su capacidad para operar en los contextos en los que se instala su nueva localización. El hecho de que estas reversiones todavía puedan producir sentidos, aun cuando para lograrlo hayan optado por el camino de una modificación estructural de los aspectos narrativos y de puesta en escena analizados anteriormente, habla de su efectividad actual, como así también de sus méritos intrínsecos, ubicados más allá de las modas o de los registros hegemónicos.

\section{BIBLIOGRAFÍA}

Aguilar, G. (2010). Otros mundos. Un ensayo sobre el nuevo cine argentino (2da. Edición). Buenos Aires: Santiago Arcos.

Ajmat, S. (2015). La patota: similitudes y diferencias entre el original y el remake. La Nación, Suplemento de Espectáculos, 17/06/2015. Recuperado de http://www.lanacion.com.ar/1801305-la-patotasimilitudes-y-diferencias-entre-la-original-y-la-remake

Amado, A. (2009). La imagen justa. Cine argentino y politica (1980-2007). Buenos Aires: Colihue.

Anderson, P. (2016). Los orígenes de la posmodernidad. Madrid: Akal.

Aumont, J. (2013). El cine y la puesta en escena. Buenos Aires: Colihue.

Bernini, E. (2003). Un proyecto inconcluso. Aspectos del cine contemporáneo argentino. Kilómetro 111. Ensayos sobre cine, 4, 87-106.

Borges, J. L. (1996). Ficciones. En sus Obras completas. Buenos Aires: Emecé.

Cascajosa Virino, C. (2006). El espejo deformado: Una propuesta de análisis del reciclaje en la ficción audiovisual norteamericana. Revista Latina de Comunicación Social, 61, enero-diciembre, 1-17.

Daney, S. (2000). Perseverancia. Buenos Aires: El Amante.

Didi-Huberman, G. (2014). Pueblos expuestos, pueblos figurantes. Buenos Aires: Manantial.

Diz, J. y Domínguez J. M. (2015). Estrenos: Santiago Mitre habla de La patota, Los inrocks, 18/06/2015. En http://www.losinrocks.com/cine/estrenos-santiago-mitre-habla-de-lapatota\#.WMBwedLhC1t [Fecha de consulta: 22 de enero de 2017]

Duarte, E. (2015). Notas dispersas: «Réimon» y «La patota»: La mirada de los otros. Blog El zapato de Herzog, 5/08/2015. En https://elzapatodeherzog.wordpress.com/2015/08/05/notas-dispersasreimon-y-la-patota-la-mirada-de-los-otros / [Fecha de consulta: 3 de marzo de 2017]

Farina, A. (2008). Reportaje a Leonardo Favio. N. Revista de cultura, 07/06/2008. en http://edant.revistaenie.clarin.com/notas/2008/06/07/01688595.html [Fecha de consulta: 22 de enero de 2017]

Font, D. (2000). La última mirada. Testamentos fílmicos. Valencia: Ediciones de La Mirada.

Gester, J. (2015). «Paulina», Cry for me Argentina. Libération, 15/05/2015. Recuperado de http://next.liberation.fr/cinema/2015/05/15/paulina-cry-for-me-argentina 1310195 [Fecha de consulta: 25 de febrero de 2017]

Guarner, J. L. (2006) Roberto Rossellini. Madrid: Fundamentos.

Horton, A. y McDougal, S. (eds.) (1998). Play it again, Sam: Retakes on remakes, Berkeley, University of California Press. 
Kairuz, M. (2015). En memoria de Paulina. Radar, Suplemento Cultural de Página 12, 07/06/2015. En https://www.pagina12.com.ar/diario/suplementos/radar/9-10659-2015-06-12.html [Fecha de consulta: 3 de marzo de 2017]

Klein, A. A. y Barton Palmer, R. (2016). Cycles, Sequels, Spin-offs, Remakes, and Reboots. Multiplicities in Film and Television. Texas: University of Texas Press.

Look, K. (2016). Retro-remaking: The 1980s-film cycle in contemporary Hollywood Cinema. En A. A. Klein y R. Barton Palmer (eds.), Cycles, Sequels, Spin-offs, Remakes, and Reboots. Multiplicities in Film and Television (pp. 277-298). Texas: University of Texas Press.

Losilla, C. (1993). Del barrio chino al cuento chino: Una teoría del remake en los años ochenta. Vertigo. Revista de cine, 7, 35-43.

Oubiña, D. y Aguilar, G. (1993). De como el cine de Leonardo Favio cantó el dolor y el amor de su gente, emocionó al carinoso público, trąó nuevos rumbos para entender la imagen y otras reflexiones. Buenos Aires: Nuevo Extremo.

Peña, F. M. (2003). Generaciones 60/90. Cine argentino independiente. Buenos Aires: MALBA/Fundación Constantini.

Reynolds, S. (2012). Retromanía. La adicción del pop a su propio pasado. Buenos Aires: Caja negra.

Schettini, A. (1995). Pasen y vean. La vida de Favio. Buenos Aires: Sudamericana.

Soler, I. (2015). La patota: Sincronía, ideología y fin de ciclo. La nota. Periodismo popular, 15/06/2015. Recuperado de https://notas.org.ar/2015/06/15/la-patota-santiago-mitre-sincronia-ideologia/ [Fecha de consulta: 31 de enero de 2017]

Verevis, C. (2006). Film remakes. Edinburgh: Edinburgh University Press.

Vieytes, Ma. del C. (2000). Encuesta: Las cien mejores películas del cine argentino. La mirada cautiva, 4, 2-32.

Zunzunegui, S. (1996). La mirada cercana. Microanálisis fílmico. Barcelona: Paidós.

\section{LISTADO DE FILMES MENCIONADOS}

All about my wife (Kyu-dong Min, 2012)

Aniceto (Leonardo Favio, 2007)

Busco novio para mi mujer (Enrique Begne, 2016)

Carancho (Pablo Trapero, 2010)

Criminal (Gregory Jacobs, 2004)

Crónica de un niño solo (Leonardo Favio, 1965)

El dependiente (Leonardo Favio, 1969)

El estudiante (Santiago Mitre, 2011)

El secreto de sus ojos (Juan José Campanella, 2009)

El secreto de una obsesion (Secret in their eyes, Billy Ray, 2015)

Elsa \& Fred (Marcos Carnevale, 2005)

Elsa \& Fred (Michael Radford, 2014)

Este es el romance del Aniceto y la Francisca, de cómo quedó trunco, comenzó la tristeza y unas pocas cosas más... (Leonardo Favio, 1966)

Europa '51 (Roberto Rossellini, 1952)

Gatica, «el mono» (Leonardo Favio, 1993)

Juan Moreira (Leonardo Favio, 1971)

La Mary (Daniel Tinayre, 1974)

La patota (Daniel Tinayre, 1960) 
La patota (Santiago Mitre, 2015)

Leonera (Pablo Trapero, 2008)

No eres tú soy yo (Alejandro Springall, 2010)

No sos vos soy yo (Juan Taratuto, 2004)

Nueve reinas (Fabián Bielinsky, 2001)

Perón, sinfonía de un sentimiento (Leonardo Favio, 1999)

Relatos salvajes (Damián Szifrón, 2014)

Se busca novio... para mi mujer (Diego Rougier, 2017)

Un fidanzato per mia moglie (Davide Marengo, 2014)

Un novio para mi mujer (Juan Taratuto, 2008)

\section{Fonseca, Journal of Communication}

